\title{
The influence of extraction methods on the quality characteristics of red wines
}

\author{
Natalia Shmigelskaya, Sofia Cherviak* , Aleksandr Makarov, Galina Sivochoub and \\ Antonina Vesyutova \\ All-Russian National Research Institute of Viniculture and Winemaking "Magarach" of RAS, Kirova \\ Str, 31, Yalta, 298600, Republic of Crimea, Russian Federation
}

\begin{abstract}
The main technological task in the production of high-quality red wines is to ensure favourable conditions for the extraction of components from solid elements of a grape bunch. Present work is devoted to the study and comparative assessment of the effect of various extraction methods (carbonic maceration of the must, carbonic maceration of grapes, pre-fermentative maceration of the must) on the quality characteristics of red wines prepared from grape varieties 'Cabernet-Sauvignon', 'Syrah' and 'Merlot'. The positive effect of the methods of carbonic maceration of both must and grapes was established in relation to the accumulation of ethyl alcohol (by $0.5-0.9 \%$ ), as well as biologically active substances: flavan-3ols ((+)-D-catechin and (-)-epicatechin) and oxycoric (caftaric and cautaric) acids - by 1.5-1.8 times compared to the classical technology. Therefore, the carbonic maceration method provides a less intensive course of oxidative processes at the stage of must, which causes the preservation of oxycoric acids in wine. Carbonic maceration of must provide a higher content of the reduced extract (up to 15\%), effective extraction of anthocyanins (from 9 to 145\%) and phenolic compounds (by 7-25\%), which manifest itself through the increase in the color intensity index (up to $26 \%$ ).
\end{abstract}

\section{Introduction}

Under the current competitive market conditions, wine producers strive to produce a quality product with distinctive characteristics. In order to achieve this goal, winemakers use various factors, such as soil and climatic conditions of growing and technological methods of growing grapes [1-3], peculiarities of the yeast strain [4-5], processing modes and methods [5-8], etc. For the quality assessment of the finished products, the standardized indicators are mainly used (volume fraction of ethyl alcohol, mass concentration of the reduced extract), as well as criteria for the sensory analysis of wines. At the same time, these indicators are not enough for a deeper study of the course of redox processes in the production of red wines. As promising additional criteria for assessing the intensity of redox processes at the stage of grape processing and fermentation, one can use the quantitative content of hydroxycinnamic acids (caftaric and cautaric acids), which are

*Corresponding author: $\underline{\text { Sofi4@@list.ru }}$ 
substrates of the oxidative polyphenol oxidase enzyme in grapes. In addition, red wines are a valuable source of biologically active components [9], among which phenolic compounds with high antioxidant activity are distinguished: $(+)$ - catechin, $(-)$ - epicatechin, caffeic acid, resveratrol, quercetin, etc. [10-12], the quantitative content of which can also be an informative criterion for product characteristics. In this regard, in the production of highquality red wines, a special attention is paid to technological methods that allow the intensifying of the extraction processes, since the color saturation and fullness of the wine's taste are ensured as a result of the maximum extraction of the components of the phenolic complex from the solid parts of the berry. Such techniques include: prolonged infusion of the must and heat treatments. The disadvantages of these operations include partial oxidation of phenolic components and the appearance of tones of heated flavor, respectively. A promising method for the production of red wines is the method of carbonic maceration, which, according to studies, makes it possible to obtain wines with a distinctive character, with a harmonious balance, with a developed aroma and taste [13], however, the effect of this method on the accumulation of biologically active compounds has not been sufficiently studied, which determines the relevance our research.

The aim of this work was to study the influence of technological methods of carbonic maceration of must and grapes on the quality indicators of red wines, including the profile of the phenolic complex.

\section{Materials and methods}

\subsection{Procedure and conditions of the experiment}

The objects of our research were samples of wines produced during the 2020 winemaking season from Cabernet Sauvignon, Merlot and Syrah grapes growing in the natural foothill region of the Crimea (Simferopol district). The sum of active temperatures for the growing season in this area was $3308{ }^{\circ} \mathrm{C}$, the amount of precipitation for the year was $400 \mathrm{~mm}$. Experimental studies were carried out in the technology department of the Institute Magarach.

The research scheme included two experimental extraction methods (carbonic maceration of must (crushed grapes) and full bunches of grapes) and a control scheme with infusion of must (Fig. 1). The technological scheme of wine preparation is shown in the picture. A distinctive feature of the technology of carbonic maceration of both must and grapes is the exclusion of the stages of sulfitation and the introduction of a pure yeast culture at the first stage of fermentation; the process was carried out in closed tanks under $\mathrm{CO}_{2}$ pressure $(\mathrm{P}=0.01-0.03 \mathrm{MPa})$ at a temperature of $30{ }^{\circ} \mathrm{C}$. The excess pressure was created with the help of carbon dioxide of exogenous origin. The fermentation process in a $\mathrm{CO}_{2}$ atmosphere was carried out until the accumulation of ethyl alcohol reached concentration of $2 \%$ volume, after that a solution of pure yeast culture (PYC) was added to the must and grapes in an amount of $3-4 \%$ and the fermentation process was continued by the submerged cap method at a temperature of $22{ }^{\circ} \mathrm{C}$. At a mass concentration of residual sugars of 30-50 g/l, wine and pomace was separated by draining (dejuicing and pressing) with the selection of wine at the rate of obtaining $55 \mathrm{daL}$ from one ton of grapes and then it was sent for after-fermentation.

As a control, the traditional method of producing red wines with the infusion of must (18 hours at a temperature of $18^{\circ} \mathrm{C}$ ) was used. Fermentation was carried out using a pure culture yeast of the Cabernet-5 race from Magarach collection of winemaking microorganisms. 


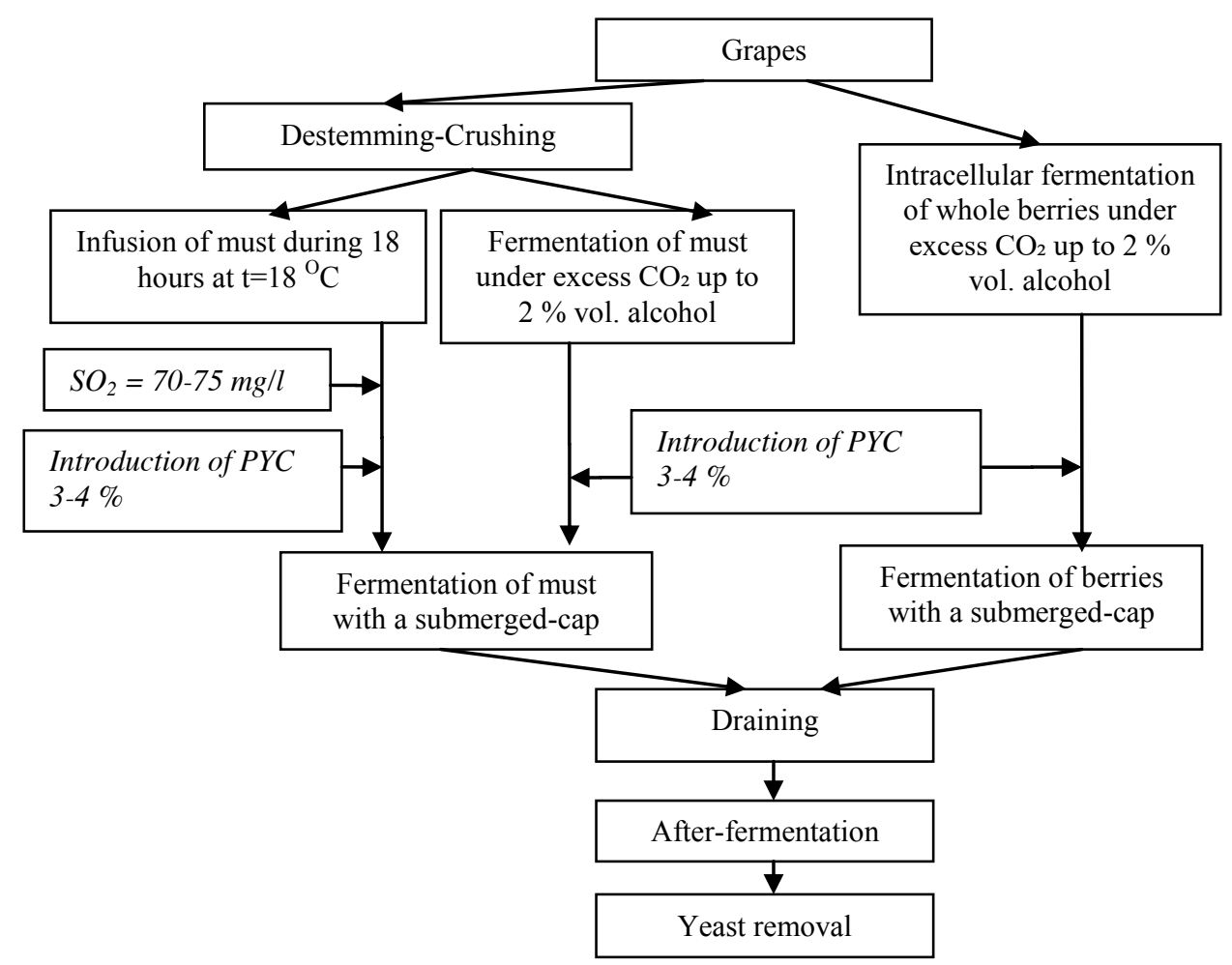

Fig. 1. Technological scheme for obtaining experimental wines

\subsection{Sample preparation and chemical analysis of wines}

These qualitative indicators were evaluated in the wines: $\mathrm{pH}$, volume fraction of ethyl alcohol, mass concentration of the reduced extract, titratable acids, sugars, phenolic substances, coloring substances [14].

The volume fraction of ethyl alcohol was determined by the hydrometric method in the distillate obtained by distillation of a wine sample. The content of titratable acids was evaluated by direct titration in terms of tartaric acid. The mass concentration of the reduced extract was determined by the hydrometric method.

The quantitative and qualitative composition of the polyphenol complex in the studied samples was determined by HPLC using the AgilentTechnologies system (model 1100) with a diode-matrix detector. A Zorbax SBC18 chromatographic column was used for the separation of substances; chromatograms were recorded at the following wavelengths: 280 $\mathrm{nm}$ for gallic acid, (+)-D-catechin, (-)-epicatechin and procyanidins, $313 \mathrm{~nm}$ for hydroxycinnamic acids derivatives, $371 \mathrm{~nm}$ for quercetin and $525 \mathrm{~nm}$ for anthocyanins. The substances were identified by comparing their spectral characteristics in terms of retention time with similar characteristics of the standards. Gallic acid, caffeic acid, (+)-D-catechin, malvidin 3-O-glucoside chloride, quercetin dihydrate, isoquercitrin (FlukaChemie AG, Switzerland), (-)-epicatechin, syringic acid (SigmaAldrich, Switzerland) were used as standards.

Sensory analysis of wines was carried out on a 100-point scale method according to the following indicators: aroma, taste and color. 
The color characteristics of the wines were evaluated by the intensity (I) and hue (T) of the color, as well as using the three-dimensional coordinate system CIELab. The optical density values of the studied wines were measured using a Specord 40 spectrophotometer (Analytik Jena, Germany) in a cuvette with an optical layer thickness of $1 \mathrm{~mm}$. The measurement of optical parameters for calculating the trichromatic coordinates $\mathrm{L}^{*}, \mathrm{a}^{*}, \mathrm{~b}^{*}$ was carried out in a cuvette with a distance between the working faces of $2 \mathrm{~mm}$. All definitions were carried out with an accuracy of the third decimal place. The X, Y, and Z coordinates were calculated using the modified Pérez-Caballero V. et al. method, taking into account the optical density of the samples at wavelengths of 450, 520, 570 and $630 \mathrm{~nm}$ [15]. The reproduction of the color expressions of the wines based on the trichromatic color coordinates $\mathrm{L}^{*}, \mathrm{a}^{*}$ and $\mathrm{b}^{*}$ was carried out using a color converter under the following conditions: the observer's measurement angle is $10^{\circ}$, the standard light source is D65 [16].

The studies were carried out in three-time replication of every variant of the experiment.

\subsection{Statistical analysis of the data}

All chemical analyses were performed in triplicate. The entries were mathematically processed with the help of statistical software package SPSS Statistics 17.0. Arithmetic mean value, variance of a single result and standard deviation (SD) were determined.

\section{Results and Discussion}

The analysis of the studied wines by physico-chemical indicators proves a positive effect of the method of carbonic maceration (both must and grapes) on the process of alcoholic fermentation, which is expressed in a higher content of ethyl alcohol (by 0.3-0.9 \%) compared to the traditional technology (Table 1). The studied samples did not differ significantly in the representation of titratable acids - regardless of the variant of the experiment, the discrepancy between the values of the indicators was $0.1-0.4 \mathrm{~g} / \mathrm{l}$. It is noted that the carbonic maceration of must provide a higher content of the reduced extract (up to $15 \%$ ) compared to other variants of the experiment. This trend is observed regardless of the grape variety.

Table 1. Physicochemical and organoleptic characteristics of wines.

\begin{tabular}{|c|c|c|c|c|c|c|c|c|}
\hline \multirow{3}{*}{$\begin{array}{l}\text { Grape } \\
\text { variety }\end{array}$} & \multirow{3}{*}{ No* } & \multirow{3}{*}{$\begin{array}{c}\text { volume } \\
\text { ratio of } \\
\text { ethyl } \\
\text { alcohol, \% }\end{array}$} & \multicolumn{4}{|c|}{ Mass concentration of } & \multirow{3}{*}{$\mathbf{p H}$} & \multirow{3}{*}{$\begin{array}{l}\text { TA*** } \\
\text { point }\end{array}$} \\
\hline & & & \multirow{2}{*}{$\begin{array}{l}\text { titratable } \\
\text { acids, } g / 1\end{array}$} & \multirow{2}{*}{$\begin{array}{l}\text { total dry } \\
\text { extract, } \mathrm{g} / \mathrm{l}\end{array}$} & \multicolumn{2}{|c|}{$\begin{array}{c}\text { phenolic } \\
\text { compounds, mg/l }\end{array}$} & & \\
\hline & & & & & total & \begin{tabular}{|c|} 
colouring \\
substances
\end{tabular} & & \\
\hline \multirow{3}{*}{$\begin{array}{l}\text { Cabernet- } \\
\text { Sauvignon }\end{array}$} & 1 & 9.8 & 11.7 & 27.4 & 1543 & 237 & 2.72 & 86 \\
\hline & \begin{tabular}{|l|}
2 \\
\end{tabular} & 10.5 & 11.6 & 27.6 & 1680 & 259 & 2.74 & 83 \\
\hline & 3 & 10.3 & 11.6 & 26.0 & 1529 & 131 & 2.74 & 79 \\
\hline \multirow{3}{*}{ Merlo } & 1 & 12.0 & 7.3 & 26.9 & 1441 & 286 & 2.91 & 85 \\
\hline & 2 & 12.9 & 7.1 & 27.9 & 1542 & 337 & 2.97 & 81 \\
\hline & 3 & 12.3 & 6.9 & 25.2 & 1473 & 157 & 3.01 & 79 \\
\hline \multirow{3}{*}{ Syrah } & 1 & 9.6 & 8.6 & 26.7 & 1053 & 275 & 2.81 & 81 \\
\hline & 2 & 10.2 & 8.3 & 28.6 & 1123 & 287 & 2.79 & 86 \\
\hline & 3 & 10.3 & 8.5 & 24.8 & 896 & 117 & 2.86 & 77 \\
\hline
\end{tabular}

*No - number of the technological scheme: 1 - traditional technology; 2 - carbonic maceration of pulp; 3 - carbonic maceration of grapes.

** TA - tasting assessment 
The results of the sensory analysis indicate a significant influence of the extraction method on the qualitative characteristics of the samples: according to the degree of increase in the wine tasting assessment, the studied technologies can be arranged in the following sequence: carbonic maceration of grapes $\rightarrow$ traditional technology $\rightarrow$ carbonic maceration of must.

The mass concentration of phenolic compounds in wines varied in the range of 898 $1680 \mathrm{mg} / \mathrm{l}$, including coloring - 117-337 mg/l. The minimum content of phenolic substances is characterized by samples prepared from Syrah grapes (by 1.3-1.9 times). It was found that the use of carbonic maceration of must contributes to a more intensive extraction of phenolic compounds in comparison with traditional technology (by 7-9\%) and carbonic maceration of grapes (by 5-25\%). At the same time, the important role of wine production technology for the accumulation of coloring substances is noted: the method of carbonic maceration of must most effectively provides the extraction of anthocyanins from grapes: the predominance of this component in relation to other variants of the experiment is from 9 to $145 \%$. Those wines which have been made by using the method of carbonic maceration of grapes were characterized by the minimum content of coloring substances

The obtained regularities of the formation of the phenolic complex under the influence of various technological processing schemes also affected the optical characteristics of the product (Table 2). It was found that the color intensity index is higher in experimental wines produced using the technology of carbonic maceration of must, which was caused by the better extraction of anthocyanins due to the effect of carbon dioxide on the permeability of the cell membrane of the grape skin. The minimum value of this indicator is observed in samples prepared by carbonic maceration of grapes. Statistical data processing allowed us to establish a correlation between the color intensity and the sum of phenolic $(r=0.7)$ and coloring substances $(\mathrm{r}=0.8)$.

Table 2. Values of tristimulus coordinates of wines and their color expressions.

\begin{tabular}{|c|c|c|c|c|c|c|c|}
\hline $\begin{array}{c}\text { Grape } \\
\text { variety }\end{array}$ & No & $\mathrm{I}$ & $\mathrm{T}$ & $\mathrm{L}^{*}$ & $\mathrm{a}^{*}$ & $\mathrm{~b}^{*}$ & $\begin{array}{c}\text { Color } \\
\text { expressions }\end{array}$ \\
\hline \multirow{3}{*}{$\begin{array}{c}\text { Cabernet- } \\
\text { Sauvignon }\end{array}$} & 1 & 1.35 & 0.39 & 45.6 & 62.8 & 3.6 & \\
\cline { 2 - 9 } & 2 & 1.47 & 0.39 & 43.5 & 62.9 & 6.9 & \\
\hline \multirow{3}{*}{ Merlo } & 1 & 0.94 & 0.42 & 54.9 & 55.7 & 0.5 & \\
\cline { 2 - 9 } & 2 & 1.52 & 0.4 & 42.7 & 62.7 & 8.7 & \\
\cline { 2 - 9 } & 3 & 1.07 & 0.44 & 36.9 & 60.7 & 20.5 & \\
\hline \multirow{3}{*}{ Syrah } & 1 & 1.03 & 0.38 & 51.9 & 55.3 & 7.3 & \\
\cline { 2 - 9 } & 2 & 1.04 & 0.38 & 53.1 & 59.1 & -1.3 & \\
\cline { 2 - 8 } & 3 & 0.57 & 0.45 & 67.0 & 43.7 & -2.4 & \\
\hline
\end{tabular}

A similar trend can be observed by giving a color expression to mathematical coordinates using the CIELab system and a color converter. According to the magnitude of the lightness $\mathrm{L}^{*}$ and the coordinates $\mathrm{a}^{*}$ and $\mathrm{b}^{*}$, which represent the hue and saturation along the red/green and blue/yellow axes, the wines obtained by the method of carbonic maceration of the must and the classical method differ slightly, with the exception of the experiment variant No. 2 from Merlot grapes, which was characterized by a more saturated color. It should be noted that a distinctive feature of wines made from Syrah grapes is the predominance of blue pigments in the color of the wine, which is confirmed by negative values of the $b^{*}$ index. 
Analysis of the profile of the phenolic complex of wines is presented in table. 3 . Flavones in the studied wines are represented by quercetin and quercetin-3-O-glycoside, which are widely used in medicine as a capillary-strengthening agent, especially in cardiovascular disease, and can also be used as an adjuvant in the treatment of inflammatory diseases and oxidative stress [17]. It is pointed out that the mass concentration of quercetin-3-O-glycoside is in a fairly wide range of $18.7-61.8 \mathrm{mg} / \mathrm{l}$, and the mass concentration of quercetin is in the range of $8.0-28.9 \mathrm{mg} / \mathrm{l}$. Data analysis indicates that the crushing of grapes provides the best extraction of the examined components obtained from the skins of grape berries. Under the conditions of carbonic maceration of grapes, there is a lower accumulation of quercetin and quercetin-3-o-glycoside (almost 2 times) in comparison with other technologies.

Table 3. Profile of the phenolic complex of wine.

\begin{tabular}{|c|c|c|c|c|c|c|c|c|c|}
\hline \multirow{2}{*}{$\begin{array}{l}\text { Grape } \\
\text { variety }\end{array}$} & \multirow{2}{*}{ No } & \multicolumn{2}{|c|}{ Flavones } & \multicolumn{2}{|c|}{ Flavan-3-ols } & \multicolumn{2}{|c|}{$\begin{array}{c}\text { Hydroxy- } \\
\text { cinnamic acids }\end{array}$} & \multicolumn{2}{|c|}{\begin{tabular}{|c|c|} 
Hydroxybenz \\
oic acids
\end{tabular}} \\
\hline & & $\begin{array}{r}\text { Quercetin-3- } \\
\text { O-glycoside }\end{array}$ & $\begin{array}{c}\text { Querceti } \\
\text { n }\end{array}$ & i $\begin{array}{c}(+)-D- \\
\text { Catechin }\end{array}$ & $\begin{array}{c}(-)- \\
\text { Epicatechin }\end{array}$ & $\begin{array}{c}\text { Caftaric } \\
\text { acid }\end{array}$ & $\begin{array}{c}\text { Cautari } \\
\text { acid }\end{array}$ & $\begin{array}{c}\text { Gallic } \\
\text { acid }\end{array}$ & $\begin{array}{l}\text { Syringic } \\
\text { acid }\end{array}$ \\
\hline \multirow{3}{*}{$\begin{array}{l}\text { Cabernet- } \\
\text { Sauvignon }\end{array}$} & 1 & 53.45 & 19.09 & 21.65 & 10.11 & 67.7 & 22.26 & 15.26 & 4.96 \\
\hline & 2 & 59.95 & 21.42 & 30.18 & 14.94 & 111.1 & 36.43 & 20.30 & 5.66 \\
\hline & 3 & 28.17 & 7.94 & 29.06 & 11.53 & 119.2 & 33.34 & 18.84 & 4.27 \\
\hline \multirow{3}{*}{ Merlo } & 1 & 56.29 & 26.36 & 43.05 & 15.05 & 29.3 & 10.47 & 27.25 & 5.14 \\
\hline & 2 & 61.84 & 28.29 & 58.57 & 21.57 & 50.0 & 18.04 & 39.08 & 6.71 \\
\hline & 3 & 33.76 & 19.16 & 50.53 & 18.21 & 52.4 & 15.85 & \begin{tabular}{|l}
32.77 \\
\end{tabular} & 4.22 \\
\hline \multirow{3}{*}{ Syrah } & 1 & 44.74 & 22.45 & 12.33 & 14.31 & 49.3 & 24.45 & 15.03 & 6.51 \\
\hline & 2 & 52.76 & 28.87 & 16.31 & 18.38 & 73.2 & 40.57 & 19.30 & 7.25 \\
\hline & 3 & 18.65 & 11.05 & 15.09 & 17.40 & 77.2 & 40.86 & \begin{tabular}{|l}
20.76 \\
\end{tabular} & 5.17 \\
\hline
\end{tabular}

From the group of flavan-3-ols, (+)- D-catechin in the amount of 15.1-58.6 mg/l and (-)epicatechin - 10.1-21.6 mg/l were identified, they have the highest antioxidant activity among phenolic compounds. The minimum concentration of $(+)$-D-catechin is noted in the Syrah grape variety, and the highest is in the Merlot variety. For most wines produced by the method of carbonic maceration of the must and grapes, the mass concentration of the studied components is higher than with the classical technology. The same trend can be traced in the content of oxycoric acids (caftaric and cautaric) - their concentration increases by 1.5-1.8 times. The obtained results indicate that the methods of carbonic maceration of the must and grapes provide a less intensive course of oxidative processes at the must stage, which causes a higher content of the examined components in the wine.

Among the hydroxybenzoic acids, gallic and syringic acids have been identified, they favorably affect the level of cholesterol in human blood [10-12]. It is found that according to the degree of accumulation of gallic acid, the studied technologies can be arranged in the following sequence: traditional technology $\rightarrow$ carbonic maceration of grapes $\rightarrow$ carbonic maceration of must.

\section{Conclusion}

Therefore, as a result of the conducted research, it is shown that this production method has a significant impact on the quality characteristics of wines. The positive effect of carbonic maceration methods of both must and grapes, considering the accumulation of ethyl alcohol (by $0.5-0.9 \%$ ), as well as biologically active substances: flavan-3-ols $((+)$-D-catechin and (-)-epicatechin) and oxycoric (caftaric and cautaric) acids - by 1.5-1.8 times compared to the classical technology. Consequently, the method of carbonic maceration provides a less 
intensive course of oxidative processes at the stage of the must, which causes the preservation of hydroxycinnamic acids in wine.

Carbonic maceration of must provide a higher content of the reduced extract (up to $15 \%$ ), effective extraction of anthocyanins (from 9 to $145 \%$ ) and phenolic compounds (by $7-25 \%$ ), which manifest itself through the increase in the color intensity index (up to $26 \%$ ). In addition, the advantages of this method include an elevated accumulation of hydroxybenzoic acids.

The obtained data indicate a positive effect of the carbonic maceration method as for the increasing of the red wines antioxidant properties due to the accumulation of biologically active substances, which can be used in the development of functional wines with the advanced biological properties.

\section{References}

1. Li Wanping, Yao Heng, Ch. Keqin, Ju. Yanlun, Min Zhuo, S. Xiangyu, Ch. Zhenglong, L. Zusong, Zh. Kekun, F. Yulin, Food Chemistry, 351, 129308 (2021).

2. Xu Weina, L. Bo, W. Congcong, K. Xiangjun, LWT, 120, 108894 (2020)

3. G. Gutiérrez-Gamboa, W. Zheng, F. Martínez de Toda, Food Research International, 139, 109946 (2021).

4. F. Ilieva, S.K. Veličkovska, V. Dimovska, H. Mirhosseini, H. Spasov, Food Chemistry, 216, 309-315 (2017).

5. A. Massera, M. Assof, S. Sari, I. Cklic, L. Mercado, V. Jofré, M. Combina, LWT, 142,111069 (2021)

6. A. Wojdyło, J. Samoticha, J. Chmielewska, Food Chemistry, 339, 127888 (2021)

7. J.O. Schelezki, G. Antalick, K. Šuklje, D.W. Jeffery, Food Chemistry, 309, 125698 (2020)

8. P. Pérez-Porras, A.B. Bautista-Ortín, R. Jurado, E. Gómez-Plaza, LWT, 138, 110645 (2021)

9. A. Kubyshkin, Yu Ogai, I. Fomochkina, I. Chernousova, G. Zaitsev, Yu. Shramko, InTechOpen, 99-120 (2018)

10. Ad. Esteban-Fernández, Ir. Zorraquín-Peña, D. González de Llano, B. Bartolomé, M. Victoria Moreno-Arribas, Trends in Food Science \& Technology, 69 (A), 118-130 (2017)

11. N. Benbouguerra, R. Hornedo-Ortega, Fr. Garcia, T.El. Khawand, C. Saucier, Tr. Richard, Trends in Food Science \& Technology, 112, 362-381 (2021)

12. X. Sun, X. Cheng, J. Zhang, Ya. Ju, Zh. Que, X. Liao, F. Lao, Yu. Fang, T. Ma, Food Research International, 127, 108704 (2020)

13. L. González-Arenzana, R. Santamaría, R. Escribano-Viana, J. Portu, P. Garijo, I. López-Alfaro, R. López, P. Santamaría, A.R. Gutiérrez, Food Chemistry, 319, 126569 (2020)

14. Compendium of international methods of wine and must analysis (International organization of vine and wine, Paris, 2017)

15. N.S. Anikina, S.N. Cherviak, N.V. Gnilomedova, Analytics and Control. 23(2), 158167 (2019)

16. NIX Color Sensor. Color converter. [Internet]. - Available from: https://nixsensor.com/free-color-converter/ Color converter. - Date of application: 31.05.2021. 
17. Ó.A. Muñoz-Bernal, Al.J. Coria-Oliveros, LA.de la Rosa, J. Rodrigo-García, N.R. Martínez-Ruiz, S.G. Sayago-Ayerdi, E. Alvarez-Parrilla, Food Research International, 140,110069 (2021) 